\title{
How learning designs, teaching methods and activities differ by discipline in Australian universities
}

\author{
Leanne Cameron \\ Southern Cross University \\ Leanne.Cameron@scu.edu.au
}

\begin{abstract}
This paper reports on the learning designs, teaching methods and activities most commonly employed within the disciplines in six universities in Australia. The study sought to establish if there were significant differences between the disciplines in learning designs, teaching methods and teaching activities in the current Australian context, as was reported in Scott's Course Experience Questionnaire (CEQ) analysis (2006). Although it found a broad range of teaching approaches are used in all disciplines, it emerged that there was still some bias toward the traditional discipline stereotypes, which in some cases has been found to negatively affect student engagement.
\end{abstract}

Additionally, while there was a general awareness amongst study participants about the importance of responding to student evaluations of teaching, improvements to teaching and learning practice were most commonly adopted without reference to current research or professional advice, and rarely was advice sought outside their discipline. Although a small-scale study such as this could not be said to be wholly representative of the higher education sector in Australia, these initial findings might indicate a need for administrators to acknowledge the role of quality teaching in maximising student engagement and its relationship to student retention by encouraging the study of learning and teaching as a routine part of lecturers' practice.

\section{Keywords}

Learning designs, discipline differences, teaching methods, teaching activities, barriers to sharing

\section{Introduction}

The introduction of the Higher Education Standards Framework ${ }^{1}$ as part of the Tertiary Education Quality and Standards Agency (TEQSA) Act of $2011^{2}$ has firmly established the importance of Learning Design in the higher education sector in Australia. Explicit references to learning design principles include mention of the "overall coherence" of a course (TEQSA, 2013, Sec 1.7); that courses should be "designed to provide appropriate engagement by students" (TEQSA, 2013, Sec 1.7); and that academic staff delivering a course should "have an understanding of pedagogical and/or adult learning principles" (TEQSA, 2013, Sec 4.2). Additionally, the Framework outlines that higher education institutions should be monitoring student attrition rates (TEQSA, 2013, Sec 5.4).

With this clear focus on course coherence and pedagogical approaches, and how they relate to

\footnotetext{
${ }^{1}$ See www.teqsa.gov.au/teqsa-contextual-overview-hes-framework for more information on the Higher Education Standards (HES) Framework

${ }^{2}$ See $<$ www.teqsa.gov.au/about $>$ for more information on the Tertiary Education Quality and Standards Agency (TEQSA)
} 
student engagement and attrition, it is timely to revisit Geoff Scott's analysis of the Course Experience Questionnaire data (CEQ), Accessing the Student Voice (Scott, 2006), which identified the factors that students reported as promoting their engagement with the teaching in Australian universities. Scott (2006) found a positive correlation between particular learning designs, teaching methods and activities and student engagement but also noted differences between disciplines. The teaching approaches that were most favourably correlated were more "typically" used in some disciplines than others.

The research outlined in this paper sought to establish whether differences between the disciplines in learning designs, teaching methods and teaching activities, as reported by students in the CEQ in Scott's analysis in 2006, still exist in the current Australian higher education context. In order to provide another perspective, confirmation was also sought from academic staff delivering course content in six Australian universities. It was determined that if the situation remained to be as the students described, the learning designs, teaching methods and activities that have been shown to positively influence student engagement in one discipline might be explored as to their possible adoption by all disciplines to increase student engagement.

\section{Definitions}

Throughout this paper, the term "disciplines" will be used to refer to "a body of knowledge with a reasonably logical taxonomy, a specialised vocabulary, an accepted body of theory, a systematic research strategy, and techniques for replication and validation" (p. 8).

For the purpose of generalising common traits, "disciplines" will be collectively described using Stark and Lattuca's (2009) "Typical Grouping of Academic Fields." They are:

- Humanities (e.g., Classics; Literature; History; Modern Languages; Music; Philosophy.)

- $\quad$ Social Sciences (e.g., Anthropology; Economics; Geography; Political Science; Psychology; Sociology)

- $\quad$ Sciences (Anatomy; Biology; Chemistry; Computer Science; Geology; Maths; Physics)

- $\quad$ Professional Fields (e.g., Architecture; Business; Communications; Education; Engineering; Nursing; Social work)."

In this paper, the term "learning designs" will be used as defined by Donald, Blake, Girault, Datt, and Ramsay (2009). In this definition, a learning design "documents and describes a learning activity in such a way that other teachers can understand it and use it in their own context. Typically, it includes descriptions of learning tasks, resources and supports" (p. 180)/

\section{Literature}

Whilst there is a substantial amount of research on disciplinary differences in learning designs, teaching methods and activities in the higher education sector, much of the foundational work began to emerge over 20 years ago. Ratings of student satisfaction with their teaching in the UK, the US and Australia at that time reported that some disciplines rated more highly than others. For example, the teaching experienced in the Humanities and Social Sciences was consistently more highly regarded that that in the Sciences (Cashin \& Downey, 1995; Franklin \& Theall, 1995). Additionally, Braxton (1995) contended that academics in the Humanities and Social Sciences showed more interest in students' learning, student development and general undergraduate education than did lecturers in the Sciences.

During this period, it was also reported that courses with higher student participation and feedback were associated with higher student satisfaction ratings. A heavy reliance on examinations and low frequency feedback grading methods were associated with lower student satisfaction ratings (Franklin \& Theall, 1992). The Sciences were commonly found to base a high percentage of the student grade on weekly quizzes and exams whereas the Humanities emphasised essays, short answer papers, journals and attendance (Franklin \& Theall, 1992). At that time, the Sciences did not score highly in these student satisfaction surveys, as student preference was for classes that were structured to maximise student engagement and collegial interaction (Light, 1974). 
Ten years later, Neumann, Parry and Becher (2002) and Scott (2006), reported little change in regard to teaching and learning in the disciplines. For example, formative assessment was common in the Humanities and the Social Sciences and was considered preferable for student satisfaction to the emphasis on exams that was still common in the Sciences; while the Professional Fields routinely concentrated on projects, presentations and the quality of class participation. Student engagement and attrition rates reflected these findings (CEQ, 1999-2006).

Shulman (2005) identified the "signature pedagogies" that can be found in professional education: a "set of assumptions about how best to impart a certain body of knowledge and know-how" (p. 55). He noted that these were pervasive and sometimes persisted even when they were no longer effective. This was attributed to the fact that lecturers in higher education most often had no formal teacher training so usually taught as they had been taught themselves.

More recently, Salmon and Wright (2014) cited three separate studies (viz., Gregory \& Salmon, 2013; Garcia, Arias, Murri \& Serna, 2010; McQuiggan, 2012) confirming that academics are "embedded in the culture of teaching in their disciplines and usually start by teaching how they were taught" (p. 53). Discipline stereotypical behaviour was also reported by Pike, Smart and Ethington (2011) when they investigated the relationships between student engagement, learning outcomes and the disciplines.

\section{Method}

The investigation reported in this paper employed a qualitative research design with the aim of gaining a comprehensive understanding of the current Australian context. A decision was made to include both an online survey and interviews in the study because neither was considered sufficient to provide a detailed and comprehensive picture of what is a very complex environment. When used in combination, these instruments complemented each other and allowed for a more robust analysis, taking advantage of the strengths of each (Greene \& Caracelli, 1997; Tashakkori $\&$ Teddlie, 1998). The investigation addressed three research questions:

- What learning designs, teaching methods and/or teaching activities are currently being used in Australian universities?

- $\quad$ Are there differences in the learning designs, teaching methods and/or teaching activities used across the disciplines?

- $\quad$ Are there any barriers to sharing learning designs, teaching methods and/or teaching activities across the disciplines?

\section{Phases of the study}

The study data was collected in two phases:

\section{Phase 1: Online Survey}

An online survey was designed to confirm the findings from the Scott's (2006) CEQ analysis and the literature about the teaching approaches typically used currently in the disciplines to provide a broad understanding of the research problem. This approach sought to determine from those delivering the content, what learning designs, teaching methods and/or teaching activities they were currently using; how typical they thought the use of these were in their discipline; and whether their use had an established history in that discipline. Additionally, information was also sought about whether learning designs and teaching methods were discussed and shared between lecturers in the discipline. Themes of interest were drawn from the survey and then targeted in the interviews that followed. 


\section{Phase 2: Interviews}

The interviews that followed were designed to refine and explain the survey results by investigating the findings in more depth (Creswell, 2003; Tashakkori \& Teddlie, 1998). That is, to determine why the learning designs, teaching methods and activities were typically used and to explore the interviewees' (lecturers) knowledge of the designing for learning process.

\section{Learning designs in current use}

Although typical patterns of use of learning designs within disciplines had previously been reported in the CEQ analysis (Scott, 2006) and confirmed in the literature (Cameron, 2013), this survey was conducted to determine if current Australian lecturers' behaviours were consistent with those findings from the previous decade.

\section{Phase 1: Online Survey}

The challenge to recruiting survey participants was the difficulty in contacting them as the oft-used route of the researcher sending out an offer via teaching and learning mailing lists, teaching and learning conferences, and prior professional development courses would mean the participants had most likely been influenced by teaching and learning innovations from outside their discipline. Hence, the sample size of the survey was small $(n=14)$ but was representative across each of the four disciplines previously defined, viz., Humanities $(n=4)$, Social Sciences $(n=3)$, Science $(n=3)$ and the Professional Fields $(n=4)$. Participants in the survey represented six Australian universities from four states (15\% of Australian universities). Five of the six universities were based in capital cities while the other was located in regional NSW.

All participants taught undergraduate students, 10 also taught post-graduate courses. They most commonly taught face-to-face classes $(n=14)$ but also frequently taught in the blended mode $(n=12,85.71 \%)$. Each participant taught groups of 15-30 students whilst 5 also lectured large groups $(90+)$. The teaching experience of the participants ranged from 1 year to 28 years.

To make identification of participants' discipline clear to the reader, they have been coded as "Participant Humx" for Humanities, "Participant SSx" for Social Sciences, "Scix" for Science, and "PFx" for Professional Fields, where " $\mathrm{x}$ " is a number allocated to differentiate between participants in the same discipline.

The survey consisted of three sections:

\section{Section 1: The source of pedagogical knowledge}

This section was designed to determine how lecturers' pedagogical knowledge about teaching and learning was obtained. Participants were provided a list of possible options (including "Other") from which to choose and they could select more than one option. A total of 50 responses were given (refer Figure 1). "Students' feedback" was a major source of how the survey participants determined how engaged the students were with their teaching. "Trial and error" and "Selfevaluation" were the next common sources of pedagogical knowledge, which suggests that teaching in a university can be an autonomous activity. This is further supported by the fact that in all but one case, how the subject content is delivered is at the lecturer's own discretion. 


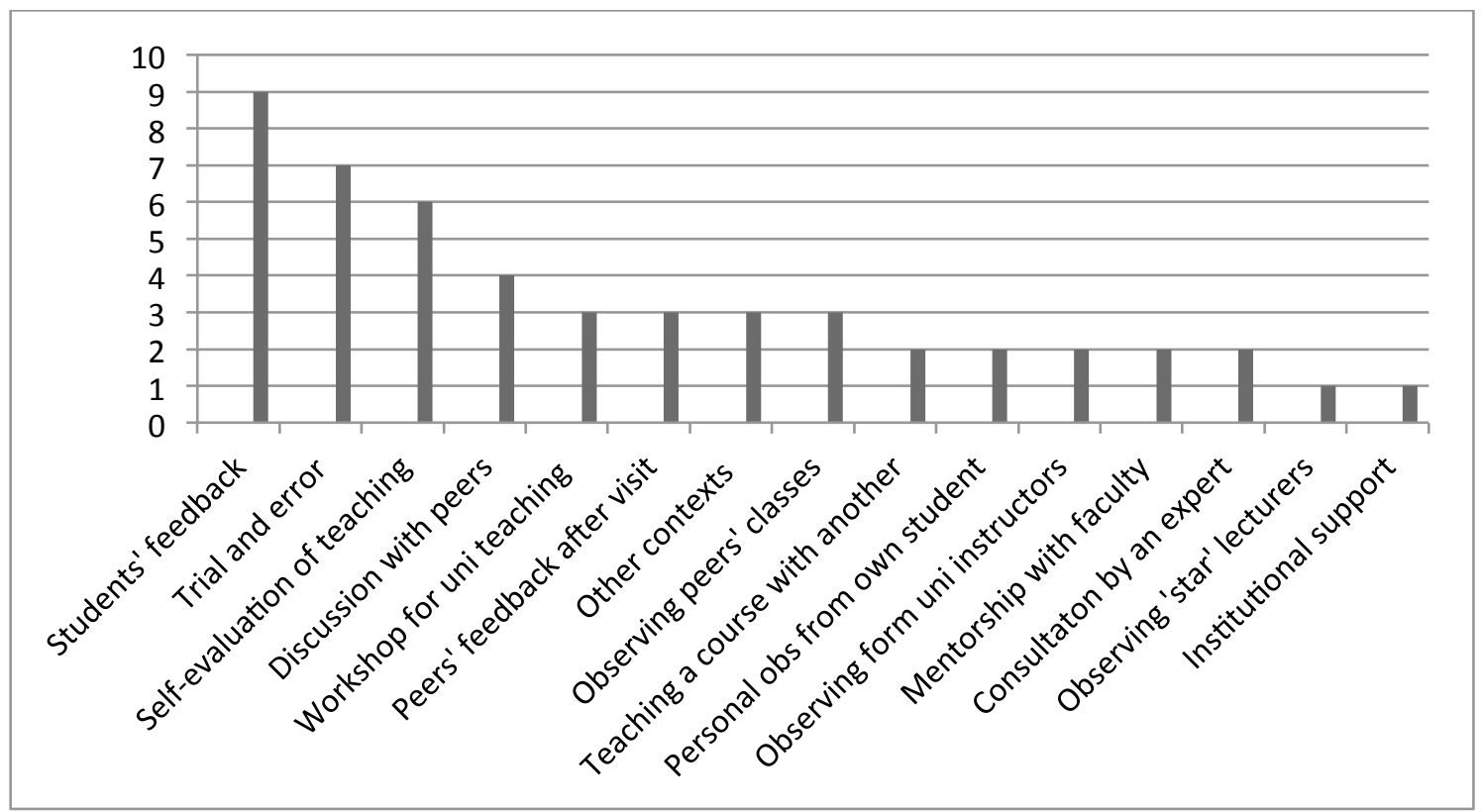

Figure 1. Source of pedagogical knowledge $(N=50)$

The next cluster of results about the source of teaching knowledge was "Discussion with peers," "Observing peers' classes," "Peers' feedback after classroom visit" and "Observing former university instructor." Thirteen of the 14 participants $(92.86 \%)$ reported discussing learning designs, teaching methods and teaching activities regularly with peers.

Interestingly, only one participant credited a centralised teaching and learning professional as a source of improving teaching knowledge ("Institutionalised support"). The reluctance of lecturers to seek out these professionals for pedagogical support with their teaching has been previously recognised (Cameron, 2013). This has implications as to how the promotion of sharing high quality learning designs, teaching methods and activities might be conducted. The findings here suggest that contextualised peer mentoring and just-in-time learning might appeal more to these lecturers than advice from centralised teaching and learning unit staff.

\section{Section 2: The characteristics of the teaching currently performed}

The CEQ analysis (Scott, 2006) and the literature (Braxton, 1995; Cameron, 2013; Cashin \& Downey, 1995; Franklin \& Theall, 1995; Neumann, et al., 2002) report that there are differences between the disciplines as to which learning designs, teaching methods and teaching activities are most commonly employed. The aim of the survey questions in this section was to confirm (or otherwise) discipline differences in the current Australian context. The survey participants were asked to report what learning designs, teaching methods and teaching activities they had used in the last 12 months (refer Figure 2).

All survey participants, regardless of discipline, reported regularly using lecture and class discussion methods. These methods are traditionally associated with teaching at university level so this was an anticipated finding. However, what was surprising was the wide range of other teaching activities reported by the participants across all disciplines. Each participant reported using two or more of the following teaching activities: Case study, Problem-based learning, Inquiry-based learning, Role play, Debating, Brainstorming, Peer tutoring, Collaborative learning, Research, Field trip/excursion and Laboratory experiments. 
Cameron

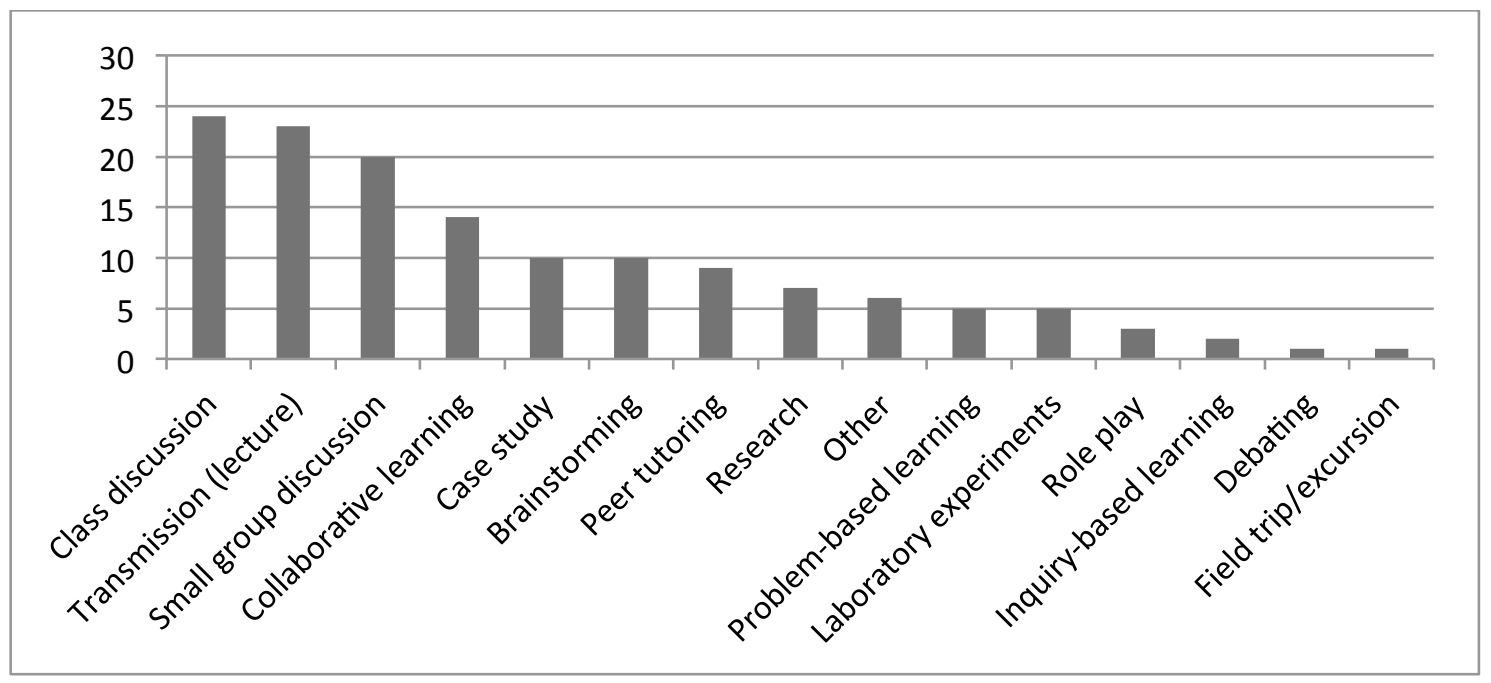

Figure 2. The learning designs, teaching methods and teaching activities used by participants in the previous 12 months $(N=140)$

Participants were also asked "What are the learning designs, teaching methods and teaching activities you use most frequently?" and "What do you consider are the benefits of using these?" The results showed the participants were very aware of the importance of student engagement. Responses included:

- $\quad$ Forums and interactive lectures. There is real benefit in interactivity. (Participant Hum1)

- I use class discussion and hands-on activities. The benefits are that the students are involved in the learning experience. (Participant PF3)

- I believe in students' generating their knowledge and understanding in collaboration with each other at their own pace. (Participant SS2)

Finding a broad range of learning designs, teaching methods and teaching activities in common usage in the Humanities and Social Sciences was to be expected, as reported in the literature (Braxton, 1995; Cameron, 2013; Neumann, et al., 2002). However, the Sciences and the Professional Fields have been acknowledged as being much more conservative in their teaching methods (Cameron, 2013; Donald, 2002). The most interesting finding in this study was that one of the participants from the Sciences nominated they used Role Play and Debating (the discipline previously reported as being the most traditional in teaching strategy). This clearly demonstrates that the teaching behaviour reported by the Science survey participants is at odds with the literature.

As our participants all answered the question, "Do you consider you are an innovative teacher?" in the positive, a conclusion could be drawn that the sample may be an atypical group. To guard against this eventuality, and to provide a more comprehensive picture, participants were also asked about the teaching methods and activities they observed were commonly used by their peers who taught alongside them in their discipline (Table 1). These results were more in line with what was reported in the literature. 
Cameron

Table 1. The learning designs, teaching methods and teaching activities most commonly used by participants' peers by discipline (in order of frequency)

\begin{tabular}{lccccc}
\hline & Hum & SS & Sci & PF & Total \\
\cline { 2 - 6 } \multicolumn{1}{c}{ Activity } & $n=4$ & $n=3$ & $n=3$ & $n=4$ & $N=14$ \\
\hline Transmission (lecture) & 4 & 3 & 3 & 4 & 14 \\
Class discussion & 4 & 3 & 3 & 4 & 14 \\
Small group discussion & 4 & 3 & 0 & 3 & 10 \\
Brainstorming & 4 & 3 & 0 & 0 & 7 \\
Peer tutoring & 4 & 3 & 0 & 0 & 7 \\
Research & 4 & 0 & 0 & 0 & 4 \\
Case study & 2 & 0 & 0 & 2 & 4 \\
Inquiry-based learning & 2 & 2 & 0 & 0 & 4 \\
Collaborative learning & 0 & 3 & 0 & 0 & 3 \\
Laboratory experiments & 0 & 0 & 3 & 0 & 3 \\
Other & 0 & 2 & 0 & 0 & 2 \\
Role play & 1 & 0 & 0 & 0 & 1 \\
Debating & 0 & 0 & 0 & 1 & 1 \\
Problem-based learning & 0 & 0 & 0 & 0 \\
Field trip/excursion & 0 & 0 & 0 & 1 \\
\hline
\end{tabular}

An earlier thought that this study's participants are an unusually innovative group is supported by these findings that the teaching undertaken by their peers is more consistent with the literature (see participants and peer comparison data in Table 2). Our participants claimed more variety in learning designs, teaching method and activities in their own teaching, than that of their peers. 
Table 2. Comparison of the learning designs, teaching methods and teaching activities most commonly used by survey participants compared to peers in their discipline

\begin{tabular}{|c|c|c|}
\hline Activity & $\begin{array}{l}\text { Participants } \\
\qquad(N=14)\end{array}$ & Peer \\
\hline Transmission (lecture) & 14 & 14 \\
\hline Class discussion & 14 & 14 \\
\hline Small group discussion & 10 & 6 \\
\hline Brainstorming & 7 & 2 \\
\hline Peer tutoring & 7 & 0 \\
\hline Research & 4 & 3 \\
\hline Case study & 4 & 1 \\
\hline Inquiry-based learning & 4 & 1 \\
\hline Collaborative learning & 3 & 2 \\
\hline Laboratory experiments & 3 & 3 \\
\hline Other & 2 & 0 \\
\hline Role play & 1 & 0 \\
\hline Debating & 1 & 0 \\
\hline Problem-based learning & 1 & 1 \\
\hline Field trip/excursion & 0 & 1 \\
\hline
\end{tabular}

The participants from the Sciences, reported their peers most commonly used the lecture, class discussion and sometimes laboratory work in their teaching. In the Professional Fields, Problembased Learning, Case Study and Small Group Discussion were common but in the Humanities and Social Sciences, a much broader range of teaching methods and activities were employed. These included Case study, Inquiry-based learning, Debating, Brainstorming, Peer tutoring, Collaborative learning (SS) and Research activities (Hum).

As the literature also refers to certain traditions of teaching methods within disciplines (Cameron, 2013; Kolb, 1981; Neumann, et al., 2002; Shulman, 2005), participants were asked to report on what learning designs, teaching methods and teaching activities have been used for a long time in their discipline. Participants were provided a list of possible options (including "Other") from which to choose and they could select more than one option. In an attempt to verify this information, a further question asked participants to report on their own university experiences as students. These findings indicated much less variety and a more conservative teaching approach in the past (see Figure 3). 


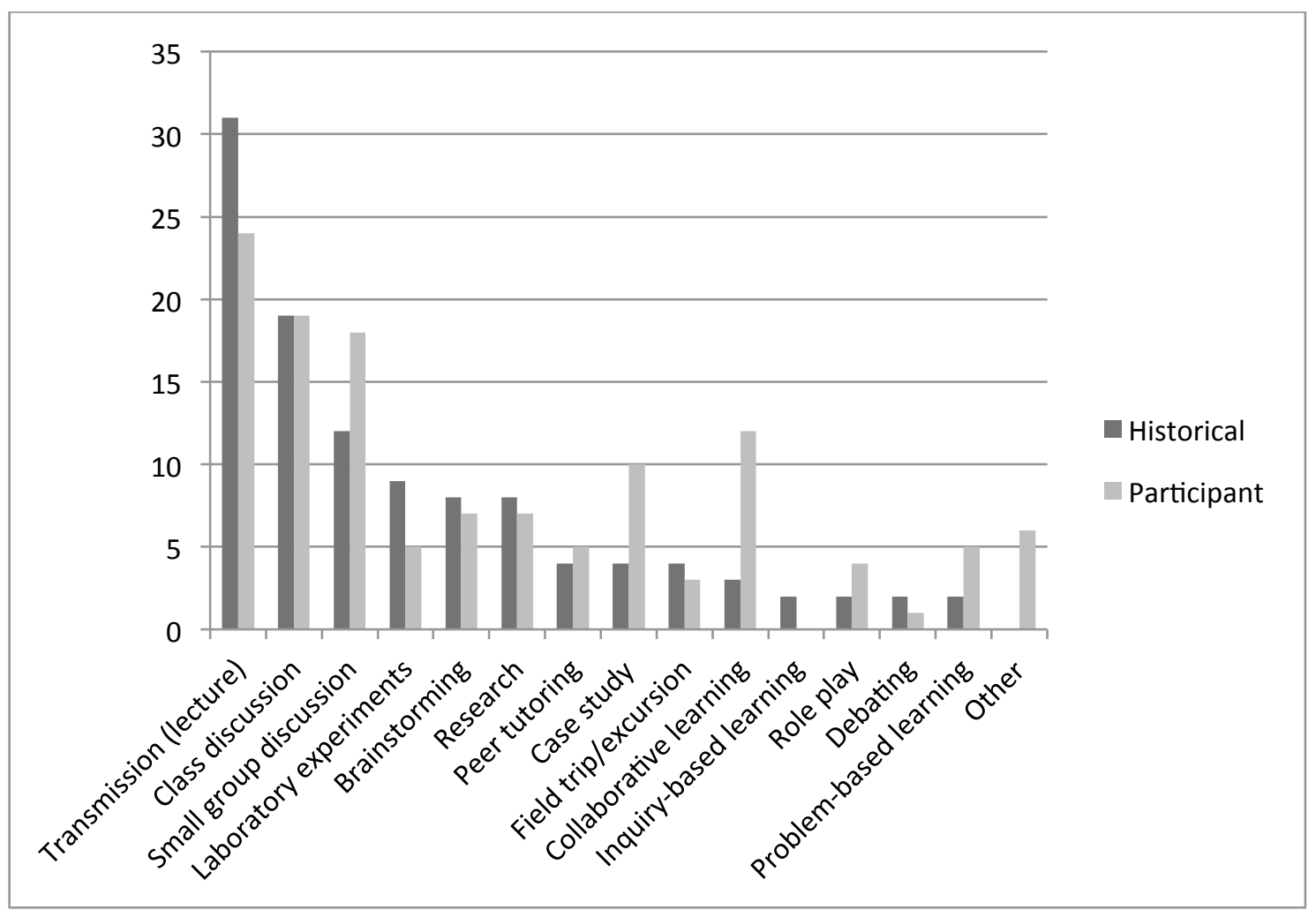

Figure 3. Comparison of learning designs, teaching methods and teaching activities used historically

\section{Section 3: Sharing learning designs, teaching methods and teaching activities}

Seven of the $14(50 \%)$ participants reported they regularly shared learning designs, discussed teaching methods and teaching activities with colleagues. Five $(35.71 \%)$ reported they sometimes shared. Only two respondents (14.29\%) reported they either rarely, or never shared learning designs, discussed teaching methods or teaching activities (refer Figure 4).

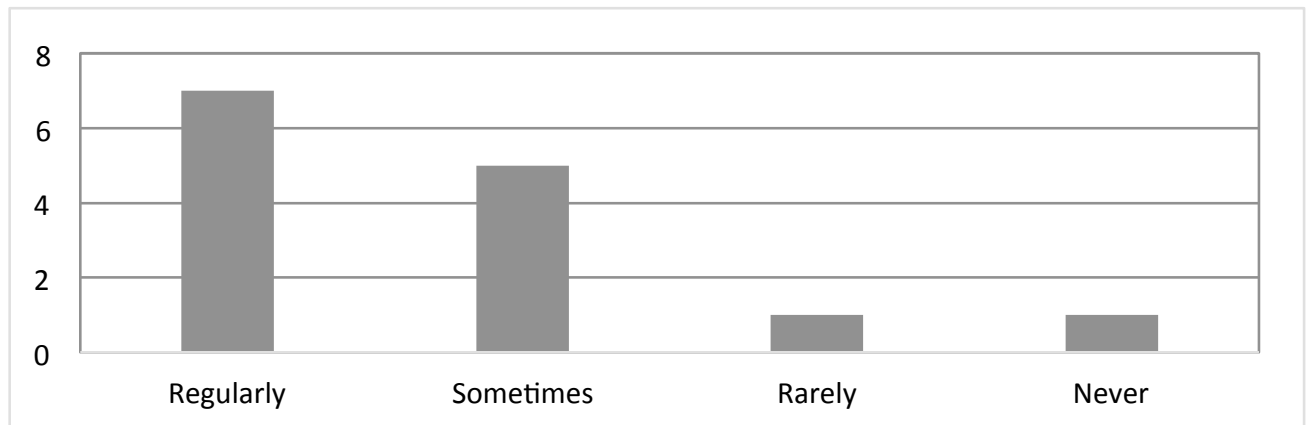

Figure 4. Sharing of learning designs, teaching methods and teaching activities with colleagues

All participants confirmed that sharing is a common practice within the discipline for them but not common across disciplines. The reason may be as simple as not having convenient access to lecturers from other disciplines. In fact, one respondent reported that "meeting other teachers is the biggest barrier to sharing."

The responses to the question, "Are there any barriers to sharing learning designs, teaching methods and/or teaching activities across the disciplines?" fell into four main categories: (i) time; (ii) students, particularly student expectations; (iii) change, particularly in regard to support from 
colleagues for change; and (iv) knowledge, particularly a lack of knowledge. The second and third categories directly related to resistance to change. Figure 5 represents the number of participants who nominated each of these identified barriers to sharing. They could nominate more than one barrier.

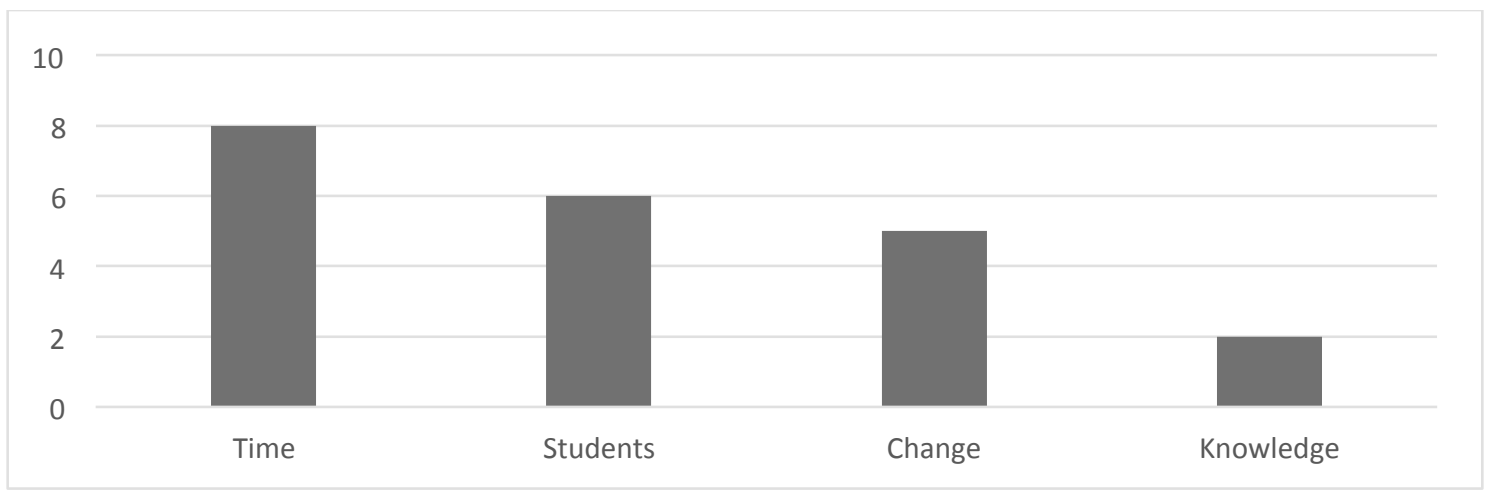

Figure 5. Barriers to sharing learning designs, teaching methods and/or teaching activities across the disciplines $(N=22)$

i. $\quad$ Time.

The majority indicated that experimenting with teaching takes time. Eight participants cited "workload issues" and/or "lack of time" as a barrier.

ii. Students' expectations.

On a number of occasions, participants reported the opposition to new teaching methods came from the students. (This was also reported in the interviews.) In a climate when positive student evaluations are highly regarded when applying for promotion positions, this can be a real barrier to sharing innovative practice:

- It takes time to change what you do and often students are resistant to change. (Participant Hum1)

- Students don't know how to adapt. (Participant SS1)

iii. $\quad$ Little support from colleagues to change

A number of participants stated that they felt quite alone when they wanted to try innovative teaching strategies and activities, with colleagues listed as a barrier to sharing teaching methods and activities:

- No-one wants to let go of the old ways. (Participant Sci3)

- Experienced teachers who think they know better are barriers. (Participant Hum1)

iv. Lack of knowledge

Two respondents reported they simply did not know enough about new strategies to understand how they could be implemented in their classroom:

- I don't know how to apply the new methods. (Participant PF1)

\section{Themes to emerge from the survey}

Major themes emerged from the survey and were determined as worthy of further exploration in the interviews. The first was that a broad range of learning designs, teaching methods and activities are currently in use in all disciplines throughout the higher education sector in Australia. With only one exception, participants reported complete autonomy with their choice in teaching approaches employed to deliver content. Additionally, most participants spoke of the value of student engagement, knowledge generation and interaction. 
Participants also reported that discussions about learning designs, teaching methods and activities with peers in their own discipline were considered very valuable, even though, like them, most of their peers did not have any formal teaching qualifications. This result was consistent regardless of the teaching experience of the participant. More information about the nature of these conversations was sought to determine if it was their peers' common understanding of the nature of their discipline that made these discussions so valuable, or whether it was simply an issue of ready access. This has important implications as to how readily teaching methods, activities and assessment tasks could be shared across the disciplines.

\section{Phase 2: Interviews}

In the second phase of the study, the themes that emerged from the earlier survey were investigated in in-depth interviews $(n=6)$. The semi-structured interview questions were designed to confirm the learning designs the interviewees typically used; explore the interviewees' knowledge of the designing for learning process and determine how learning designs, teaching methods, activities and assessment tasks were discussed and shared with others outside their own discipline. The interviews ranged from 1-2 hours in duration. The intention at this point in the study was not to be wholly representative of the entire higher education sector but simply to provide a variety of views from a range of disciplines.

\section{Interview participants}

Although the interviewees were not the same individuals as responded to the earlier online survey, they were required to have similar characteristics in that participants were academics responsible for designing for learning. Eleven lecturers were invited to be interviewed as part in the project six agreed. The interviewees came from two universities in Sydney (Australia) and their teaching experience ranged from 6 months to 30+ years. They were distributed among the disciplines as follows: Humanities $(n=2)$, Social Sciences $(n=2)$ and the Professional Fields $(n=2)$. There were no participants from the Science disciplines. The participants' teaching experience ranged from 6 months to $30+$ years. Numerous attempts were made to procure interviewees from the Sciences but an interview about their teaching did not appeal to any of the many lecturers approached.

\section{Findings from the Interviews}

Lectures and tutorials were the most commonly described mode of delivery for all interviewees with 1 or 2 hours of lectures $+2-3$ hours of smaller group tutorial per week per cohort being the typical model. In all but two cases, lectures were described as "stand and deliver" sessions whereby the lecturer primarily used this time for the transmission of content knowledge and general administration detail. Acknowledgement was made of the low engagement of many students with the traditional lecture format.

- We are looking at ways to get students to come to lectures, maybe taking a roll ... but others are just putting them online because the students don't turn up. (Interviewee SS1)

The two lecturers who did not describe their lectures this way, spoke of breaking the large group into smaller ones, and conducting small group activities as part of the larger lecture. However, all interviewees commented on the low attendance rates and lack of student engagement with the traditional lecture format:

- I know that students can't cope with lectures for too long. (Interviewee Hum1)

- I feel I have to put on a show, use lots of humour, cartoons, to keep them entertainedotherwise they can't keep their concentration going. Or they don't keep coming. (Interviewee Hum2)

The interviewees reported the most innovative teaching occurred in tutorials. Whilst three of them spoke of often conducting "traditional" tutorials, whereby the students were asked to pre-read 
material that was discussed as a group, there was a wide range of other learning designs, teaching methods and teaching activities being employed. Case-based learning (CBL) was mentioned by both Professional Field interviewees and one of those from Social Science as being an important part of tutorials:

- We always start with this [CBL] and move on to understanding the theory from the focus on the case. (Interviewee SS1)

- $\quad$ Problems require higher order thinking and allow students to engage with issues. (Interviewee PF1)

- In each case the students also look at alternative scenarios and predict what could happen. They need to provide a hypothesis and the draw conclusions. (Interviewee PF2)

Role play, SWOT (Strength, Weakness, Opportunity, Threat) analysis, presentations and a great deal of small group work were also learning designs mentioned as being used in tutorials by the interviewees. Assessments, however, tended to conform to the discipline stereotype commonly found in the CEQ analysis (Scott, 2006) and the literature (Cameron, 2013; Franklin \& Theall, 1992; Neumann, et al., 2002). The Social Science and Humanities interviewees used essays while the Professional Field studies favoured projects, exams and field experience. (There were no Science lecturers interviewed.)

- $\quad$ There is an exam, just short answer and essay topics. (Interviewee SS1)

- $\quad$ There is a test at the end - to see how effective their processes have been, and check the performance the whole semester. (Interviewee Hum1)

Approaches to designing for learning varied. Three of the six interviewees commonly worked with others to develop units, using a variety of personally developed models:

- We start work with a theme, and together we work around that. (Interviewee Hum1)

- We teach using a socio-cultural theoretical approach that looks at different issues using social justice as a frame. We start with first principles and then develop activities out of that. (Interviewee SS2)

Two interviewees developed all teaching activities alone, only rarely discussed learning designs, teaching methods, activities and assessment tasks and stated this approach was fairly typical in their discipline (PF and SS) and were quite comfortable with this process. However, another interviewee, in his second year of teaching, did not discuss his teaching activities with others and was not confident with this approach $(\mathrm{PF})$ :

- I'm just feeling my way. I even entered this study to hear more about teaching. (InterveiweePF1)

Only one interviewee had ever sought learning design assistance from a centralised teaching and learning unit in the university, despite all participants acknowledging that their own university had such a unit. That interviewee was quite happy to employ the innovation discussed at this professional learning event:

- I attended a workshop and learnt about a different way to teach large groups. I am very keen to try the model that was laid out for us. (IntervieweeSS1)

Whilst only three of the six interviewees commonly worked co-operatively with others to develop learning designs, teaching methods, activities and assessment tasks, five reported they had regular discussions with others in their own discipline about their teaching. Only one of the interviewees had had such a discussion in recent times with someone outside their own discipline - and this had 
been an informal conversation in a corridor.

All interviewees could articulate barriers to sharing new and different learning designs, teaching methods, activities and assessment tasks, both within, and across disciplines. They most commonly mentioned students' adverse reactions to innovative teaching approaches, such as problem-based learning, as being a barrier. Meeting student expectations was spoken about regularly during these interviews.

- $\quad$ Student attitudes. They want to be spoon fed, as opposed to them being responsible for their own learning. We like to try to develop their independence and critical thinking but they don't like to be asked to think. (Interviewee SS1)

- $\quad$ There is an expectation that appears to come from their schooling that the content will be provided for them and they will simply have to answer a few comprehension questions to get through. (Interviewee PF2)

Lack of time for meetings and peer disinterest were also mentioned for skepticism that sharing learning designs, teaching methods, activities and assessment tasks across disciplines might be a productive venture.

- $\quad$ Term time is busy, semester breaks are for research. At this time creative teaching is not really a priority for others. (Interviewee SS1)

- I want to work with my classes better. But it doesn't seem so important to others. They have other things they want to do. (Interviewee Hum1)

\section{Discussion}

In order that they conform to the 2013 Higher Education Standards Framework, Australian higher education institutions are being audited to ensure their teaching and learning is of high quality. Explicit references to learning design principles include mention of the "overall coherence" of a course (TEQSA, 2013, Sec 1.7), that courses should be "designed to provide appropriate engagement by students" (TEQSA, 2013, Sec 1.7) and that academic staff delivering a course should "have an understanding of pedagogical and/or adult learning principles" (TEQSA, 2013, Sec 4.2).

Despite this, participants in this study reported the use of teaching approaches in some disciplines that are not conducive to high student engagement. The CEQ data analysis (Scott, 2006) outlined the learning designs, teaching methods and activities that students find engaging and reports which disciplines in Australian universities are most successful at employing these. Sharing this research widely among academics might provide an excellent foundation to improving teaching and learning across disciplines in the higher education sector.

This study also found that widespread, informed discussion and the sharing of teaching and learning principles is not routinely taking place in all disciplines in the surveyed universities. While there was a general awareness amongst study participants about the importance of responding to student evaluation of their teaching, changes were most commonly adopted without reference to current research or professional advice. The fact that many of the colleagues whom participants consulted about their teaching had no formal teacher training was established in the interviews. Designing for learning emerged from this study as only a semi-professional activity. This finding adds some credence to Biggs's (2003) assertion that good teachers in a university are often simply "gifted amateurs."

Additionally, ensuring that teaching and learning is of high quality in our universities (as TEQSA requires) is a challenge when qualifications in teaching and learning are not always in the essential selection criteria for higher education entry-level positions. Clearly the way forward is complex. The major findings from this study highlight a problem: It has been established that the learning 
designs, teaching strategies and activities that have been proven to be highly engaging for students are not being shared across disciplines and that lecturers most commonly sourced their pedagogical knowledge from their colleagues within their own discipline. Similarly, nor were centralised teaching and learning units being accessed to source this knowledge.

It can also be concluded that developing an understanding of generic teaching and learning is not sufficient for high quality teaching and learning practices in the individual disciplines. This highlights the importance of the relationship between discipline content knowledge and pedagogical process. Shulman (1986) described three categories of content knowledge: subject matter content knowledge, pedagogical content knowledge, and curricular knowledge. Berthiaume (2009) took a more integrated approach with his Model of Discipline-specific Pedagogical Knowledge (DPK) for university teaching. This describes the relationship between a lecturer's knowledge base for teaching, disciplinary specificity and their beliefs about knowledge (Fry et al., 2009).

Regardless of the approach taken, the TEQSA Teaching and Learning quality requirements flag a need to elevate the profile of the scholarship of learning and teaching and the associated field of learning design that focusses on the study of teaching, learning and curriculum. From the evidence gained in this study, the call to introduce innovation, creativity and other soft skills, such as key graduate attributes, is being answered in many higher education tutorial classrooms. However, it is not always being undertaken as a systematic approach. What has emerged is that teaching and learning decisions are commonly being made by lecturers without familiarity of current research into practices of teaching, learning and curriculum.

\section{Conclusion}

While a study of this scale cannot be wholly representative of the entire higher education sector, it has provided a variety of views from a range of disciplines in six universities in Australia. It has been found a broad range of teaching approaches are used in all disciplines in the Australian universities surveyed, it emerged that there is still some bias toward the traditional discipline stereotypes, especially in assessment. It was found that innovative, creative and engaging teaching and learning is occurring in many tutorial classrooms but it is not being undertaken as a result of a systemic approach to quality throughout the institutions.

This study highlights the challenge of ensuring that high quality course design is developed when widespread, informed discussion of well-researched teaching approaches is not always embedded in university practice. To ensure high quality teaching and learning in all classrooms, the scholarship of learning and teaching needs to be an integral part of lecturers' teaching practice and it follows that institutions have a responsibility to provide "opportunities to improve their teaching" (TEQSA, 2013, Sec 4.2). This study also highlights the value of the study of the scholarship of learning and teaching across all disciplines and the role it might potentially have in improving student engagement and retention.

\section{References}

Berthiaume, D. (2009). Teaching in the disciplines. In H. Fry, S. Ketteridge, \& S. Marshall (Eds.). A Handbook for Teaching and Learning in Higher Education: Enhancing Academic Practice.

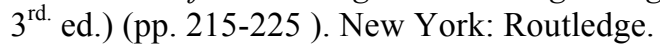

Biggs, J. (2003). Teaching for quality learning at university - What the student does ( $2^{\text {nd }}$. ed.). Buckingham, UK: SRHE / Open University Press.

Braxton , J.M. (1995). Disciplines with an affinity for the improvement of undergraduate education. In N. Hativa \& M. Marincovich (Eds.), Disciplinary differences in teaching and learning: Implications for practice (pp. 59-64). San Francisco, CA: Jossey-Bass.

Cameron, L. (2013). Giving teaching advice meaning: The importance of contextualizing pedagogical instruction within the discipline. In B. Tynan, J. Willems, \& R. James (Eds.) 
Outlooks and Opportunities in Blended and Distance Learning (pp. 50-65). Hershey, PA: Information Science Reference. doi:10.4018/978-1-4666-4205-8.ch004

Cashin, W.E., \& Downey, R.G. (1995). Disciplinary differences in what is taught and in students' perceptions of what they learn and of how they are taught. In N. Hativa \& M. Marincovich (Eds.), Disciplinary differences in teaching and learning: Implications for practice (pp. 81-92. San Francisco, CA: Jossey-Bass.

Course Experience Questionnaire (CEQ). Data can be retrieved from: http://www.graduatecareers.com.au/research/surveys/australiangraduatesurvey

Creswell, J.W. (2003). Research design: Qualitative, quantitative, and mixed methods approaches. $\left(2^{\text {nd }}\right.$. ed.). Thousand Oaks, CA: Sage.

Donald, J. (2002). Learning to think: Disciplinary perspectives. San Francisco: Jossey-Bass.

Donald, C., Blake, A., Girault, I., Datt, A., \& Ramsay, E. (2009). Approaches to learning design: Past the head and the hands to the HEART of the matter, Distance Education, 30:2,179 - 199. doi: 10.1080/01587910903023181

Franklin, J., \& Theall, M. (1992). Discipline differences: Instructional goals and activities. Measures of student performance, and student ratings of instruction. Proceedings of the Annual Conference of the American Educational Research Association. San Francisco, CA: April 2024, 1992.

Franklin, J., \& Theall, M. (1995). The relationship of disciplinary differences and the value of class preparation time to student ratings of teaching. In N. Hativa \& M. Marincovich (Eds.), Disciplinary differences in teaching and learning: Implications for practice (pp. 41-48). San Francisco, CA: Jossey-Bass.

Fry, H., Ketteridge, S., \& Marshall, S. (Eds). (2009). A Handbook for Teaching and Learning in Higher Education: Enhancing Academic Practice ( ${ }^{\text {rd }}$ ed.). New York: Routledge.

Garcia, E., Arias, M., Murri, N., \& Serna. C. (2010). Developing responsive teachers: A challenge for a demographic reality. Journal of Teacher Education, 61, 132-142.

Greene, J. C., \& Caracelli, V.J. (Eds). (1997). Advances in mixed-method evaluation: The challenges and benefits of integrating diverse paradigms [New directions for evaluation (74)]. San Francisco, CA: Jossey-Bass.

Gregory, J., \& Salmon, G. (2013). Professional development for online university teaching. Distance Education, 34, 256-270.

Kolb, D.A. (1981). Learning styles and disciplinary differences. In A. W. Chickering (Ed.), The modern American college (pp. 232-255). San Francisco, CA: Jossey-Bass.

Light, D. (1974, Winter). Introduction: The structure of the academic professions. Sociology of Education, 47(1), 2-28.

McQuiggan C. (2012). Faculty development for online teaching as a catalyst for change. Journal of Asynchronous Learning Networks, 16, 27-61.

Neumann, R., Parry, S.. \& Becher, T. (2002). Teaching and learning in their disciplinary contexts: A conceptual analysis. Studies in Higher Education, 27, 4, 405-417. doi:10.1080/0307507022000011525

Pike, G., Smart, J., \& Ethington, C. (2012). The mediating effects of student engagement on the relationships between academic disciplines and learning outcomes: An extension of Holland's Theory. Research in Higher Education, 53, 550-575.

Salmon, G., \& Wright, P. (2014). Transforming future teaching through "Carpe Diem" learning design. Education Sciences, 4(1), 52-63. doi:10.3390/educsci4010052

Scott, G. (2006). Accessing the student voice: Using the CEQuery to identify what retains students and promotes engagement in productive learning in Australian higher education. Final Report. Barton, Australia: Commonwealth of Australia. 
Shulman, L.S. (1986, February). Those who understand: Knowledge growth in teaching. Educational Researcher, 15(2), 4-14.

Shulman, L.S. (2005, Summer). Signature pedagogies in the professions. Daedalus, 134(3), 52-59. doi:10.1162/0011526054622015

Stark, J. S., \& Lattuca, L.R. (2009). Shaping the college curriculum: Academic plans in context. $\left(2^{\text {nd }}\right.$. ed). San Francisco, CA: Jossey-Bass.

Tashakkori, A., \& Teddlie, C. (1998). Mixed methodology: Combining qualitative and quantitative approaches. Applied Social Research Methods Series (Vol. 46). Thousand Oaks, CA: Sage.

Copyright $@ 2017$ Leanne Cameron 